\title{
USE OF THE ULTRASOUND GUIDED ERECTOR SPINAE BLOCK AS AN ALTERNATIVE ANESTHESIA METHOD IN A SELECTED VIDEO ASSISTED THORACOSCOPY CASE
}

$\because$ ESRA 2019

S. Tulgar ${ }^{1}$, O. Selvi ${ }^{1}$, B. Kiziltunc ${ }^{1}$, A. Orki ${ }^{2}$, A. Cosar ${ }^{2}$, Z. Ozer ${ }^{1}$.

1-Maltepe University Faculty of Medicine, Anesthesiology and reanimation, Istanbul, Turkey.

2-Maltepe University Faculty of Medicine, Department of thoracic surgery, Istanbul, Turkey.

ESRA19-0467

\section{Background and Aims:}

- Video assisted thoracoscopy (VATS) is a frequently performed under general anesthesia.

-Paravertebral block or other regional techniques could be used as an option in selected patients undergoing thoracoscopic diagnostic biopsy.

-We present the application of ultrasound guided erector spinae block (ESPB) for the management of a VATS case as a main anesthesia method

\section{Methods:}

-A 58 years old male patient who had a chest drain due to chronic right lung empyema after chemotherapy treatment due to lung cancer.

-ESPB at level of T5 was applied with outplane technique in lateral position under sedoanalgesia with midazolam $2 \mathrm{mg}$ and fentanyl $25 \mathrm{mcg}$.

-Mixture of local anesthetics composed of 20 $\mathrm{mL}$ bupivacaine $0.5 \%$ and $10 \mathrm{~mL}$ lidocaine 2 $\%$ was applied between transverse process and erector spinae muscle.

\section{Results:}

-The sensorial block between T2-T7 dermatomes was confirmed with pinprick test after 30 minutes following block application.

-Deep dermal and subcutaneous surgical tissue biopsies were sampled in 4 abdominal quadrant.

- Small lobular pathologies between lung parenchyma and thoracic wall were observed and dissected.

-The surgery lasted for 25 minutes. Additional $10 \mathrm{mg}$ intravenous ketamine was applied and repeated three times in this period of time.

\section{ESPB may be used for anesthesia in suitable diagnostic VATS cases. Further feasibility studies may be needed.}

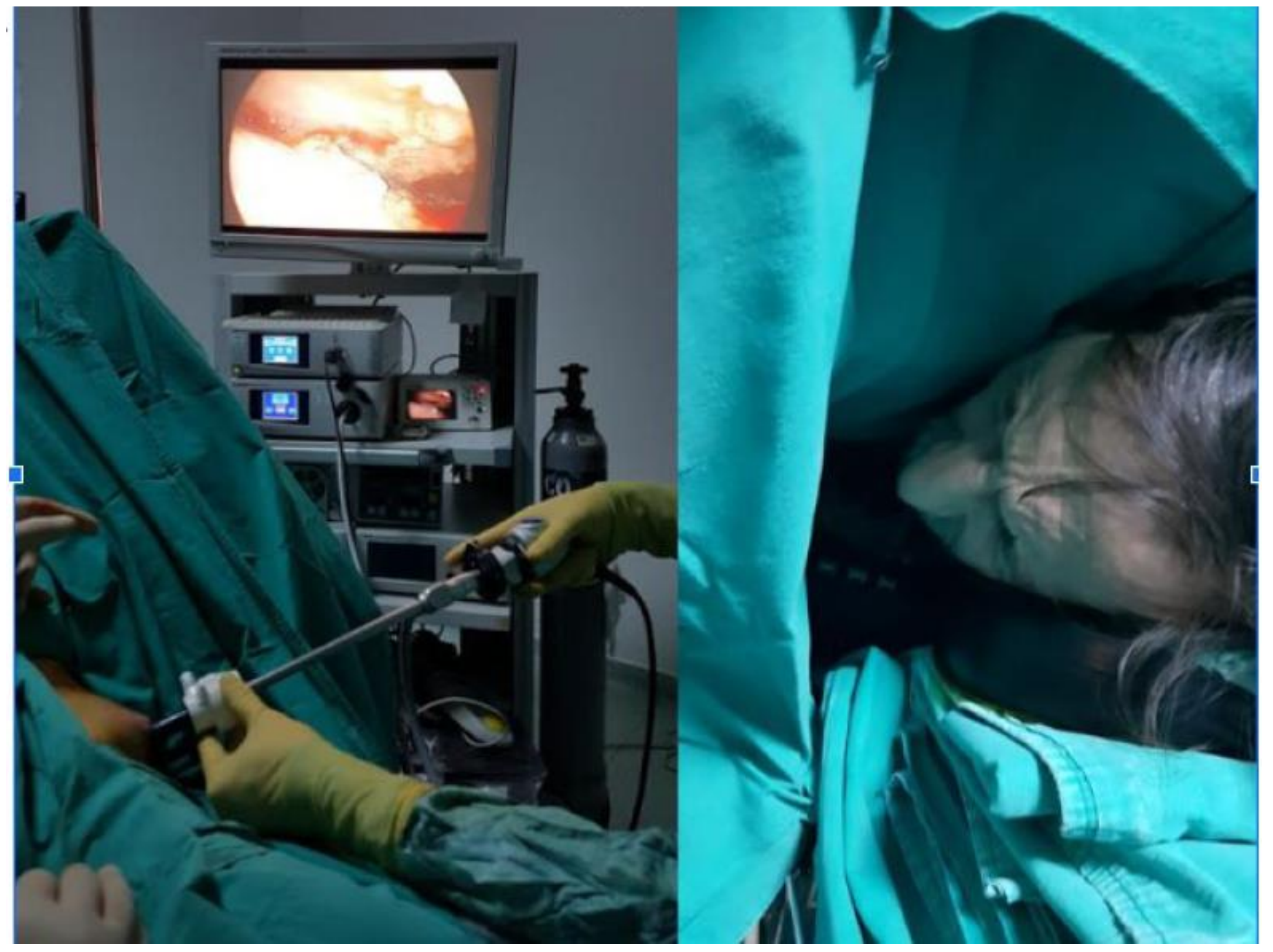

References: 1-Erector spinae plane block as an alternative to epidural analgesia for postoperative analgesia following video-assisted thoracoscopic surgery: A case study and a literature review on the spread of local anaesthetic in the erector spinae plane. Adhikary SD, Pruett A, Forero M, Thiruvenkatarajan V. Indian J Anaesth. 2018 Jan;62(1):75-78.

2-The erector spinae plane block in 4 cases of video-assisted thoracic surgery. Luis-Navarro JC, Seda-Guzmán M, Luis-Moreno C, López-Romero JL. Rev Esp Anestesiol Reanim. 2018 Apr;65(4):204-208. doi: 10.1016/j.redar.2017.12.004. 3 -Erector spinae plane block: a systematic qualitative review.

De Cassai A, Bonvicini D, Correale C, Sandei L, Tulgar S, Tonetti T.

Minerva Anestesiol. 2019 Mar;85(3):308-319. doi: 10.23736/S0375-9393.18.13341-4

Contact info: Dr. Onur Selvi prostel@yahoo.com Tel: +905337799760 